\title{
VIEWPOINT
}

\section{Learning from the Opioid Epidemic: Preventing the Next Healthcare Marketing Crisis}

\author{
Nishant Uppal, BS ${ }^{1,2}$ and Timothy S. Anderson, MD, MAS ${ }^{1,3}$ \\ ${ }^{1}$ Harvard Medical School, Boston, MA, USA; ${ }^{2}$ Harvard Business School, Boston, MA, USA; ${ }^{3}$ Division of General Medicine, Beth Israel Deaconess \\ Medical Center, 1309 Beacon Street, Brookline, Boston, MA, USA.
}

J Gen Intern Med 36(11):3553-6

DOI: 10.1007/s11606-021-06799-1

(c) Society of General Internal Medicine 2021

$\mathrm{T}$ he ongoing opioid epidemic has led to hundreds of lawsuits against opioid manufacturers alleging illegal marketing practices, which have upended the industry. While the early results of litigation should be viewed with optimism, changes in the structure and market focus of opioid manufacturers have been largely overlooked in the wake of public attention to the opioid-related settlements.

Patients and clinicians should be encouraged that recent settlements have included funding for patients with opioid use disorder and have potential to finance public health efforts to curtail the epidemic. However, there remains a notable lack of progress geared towards preventing the same aggressive and often illegal marketing practices by these and other pharmaceutical companies going forward. As opioid manufacturers restructure and pivot towards different product areas, clinicians and policy makers should be mindful that without stricter scrutiny the stage is set for history to repeat itself.

\section{STRUCTURAL CHANGES AMONG OPIOID MANUFACTURERS}

Since 2014, nearly all companies marketing opioids have been named in federal, state, and local lawsuits alleging inappropriate marketing practices that downplayed medication-related harms. In Table 1, we summarize changes to company financial structures, branding, and marketing practices obtained through a systematic search of company filings with the Securities and Exchange Commission [1]. Since no prior framework for analyzing opioid-related industry changes was available, changes were organized based on patterns that emerged from reviews of company filings. Three major trends are worth noting.

Received January 10, 2021

Accepted April 1, 2021

Published online April 26, 2021
First, several companies have sought to restructure via merger and/or acquisition, which allows for the development of more diverse drug portfolios and prevents further losses in revenue due to declines in opioid prescribing. In some cases, mergers have allowed companies to take advantage of trends towards non-opioid pain products. For example, in 2018, Egalet US stopped manufacturing Arymo ER (morphine) and acquired multiple non-steroidal anti-inflammatory drug products.

Second, companies have shifted focus from pain medications to other drug development areas. Endo Pharmaceuticals made several acquisitions to expand into urology, allergy, and dermatology drug areas. Other companies, such as BioDelivery Sciences International and Purdue Pharma, have shifted to marketing medications used to treat opioid use disorder. The latter practice has been controversial: proponents argue that developing such medications is a favorable step to addressing the national crisis, while critics decry the practice as an attempt to profit off of the problem created by opioid manufacturing/marketing.

Third, several companies have sold opioid products and reduced their presence in the national pain market. For example, Daiichi Sankyo terminated its Roxybond licensing agreement with Inspirion in order to exit the US pain market, and both Depomed (now Assertio Therapeutics) and Egalet US (now Zyla Life Sciences) changed names and decreased opioid marketing efforts, thereby distancing themselves from public attention to the opioid crisis.

\section{THE NEED FOR ONGOING SKEPTICISM OF PHARMACEUTICAL MARKETING}

There is a great risk that the actions of opioid manufacturers may be viewed as an isolated case of improper behavior that has been sufficiently addressed by large legal settlements and structural shifts away from opioid products. However, history suggests that new products are likely to be the targets of aggressive marketing by both opioid manufacturers and other pharmaceutical companies.

Pharmaceutical companies have long played a prominent role in shaping prescribing practices through marketing to clinicians and patients. Over the last two decades, pharmaceutical marketing has increased to over $\$ 25$ billion annually [2]. 
Table 1 Restructuring of Companies Marketing Opioids in the USA, 2014-2020

\begin{tabular}{|c|c|c|c|c|c|c|c|c|c|}
\hline \multirow[t]{2}{*}{$\overline{\text { Company }}$} & \multirow{2}{*}{$\begin{array}{l}\text { Named } \\
\text { in opioid } \\
\text { litigation }\end{array}$} & \multicolumn{8}{|c|}{ Restructuring } \\
\hline & & $\begin{array}{l}\text { Merged } \\
\text { or } \\
\text { acquired }\end{array}$ & $\begin{array}{l}\text { Declared } \\
\text { bankruptcy }\end{array}$ & $\begin{array}{l}\text { Changed } \\
\text { name }\end{array}$ & $\begin{array}{l}\text { Stopped } \\
\text { selling } \\
\text { opioid } \\
\text { product }\end{array}$ & $\begin{array}{l}\text { Developing } \\
\text { product to } \\
\text { treat opioid } \\
\text { use disorder }\end{array}$ & $\begin{array}{l}\text { Acquired } \\
\text { opioid } \\
\text { products }\end{array}$ & $\begin{array}{l}\text { Acquired } \\
\text { non-opioid } \\
\text { pain prod- } \\
\text { uct }\end{array}$ & $\begin{array}{l}\text { Acquired } \\
\text { non-pain } \\
\text { product }\end{array}$ \\
\hline $\begin{array}{l}\text { BioDelivery } \\
\text { Sciences } \\
\text { International* }\end{array}$ & $X$ & & & & $\mathrm{X}$ & & & & \\
\hline $\begin{array}{l}\text { Collegium } \\
\text { Pharmaceuticals }\end{array}$ & $\mathrm{X}$ & & & & & & $\mathrm{X}$ & & \\
\hline Daiichi Sankyo & & & & & $\mathrm{X}$ & & & & \\
\hline Depomed $^{\S}$ & $X$ & $\mathrm{X}$ & & $\mathrm{X}$ & $\mathrm{X}$ & & & & \\
\hline Egalet US" & X & $X$ & $X$ & $X$ & $X$ & & & $X$ & \\
\hline $\begin{array}{l}\text { Endo } \\
\text { Pharmaceuticals } \mathrm{I}^{\mathrm{I}}\end{array}$ & $\mathrm{X}$ & & & & $\mathrm{X}$ & & & $X$ & $\mathrm{X}$ \\
\hline $\begin{array}{l}\text { Galena } \\
\text { Biopharma }\end{array}$ & $\mathrm{X}$ & $\mathrm{X}$ & & & $\mathrm{X}$ & & & & \\
\hline $\begin{array}{l}\text { Insys } \\
\text { Therapeutics }\end{array}$ & $X$ & & $\mathrm{X}$ & & $\mathrm{X}$ & & & & \\
\hline $\begin{array}{l}\text { Johnson \& } \\
\text { Johnson }\end{array}$ & $X$ & & & & $\mathrm{X}$ & & & & \\
\hline $\begin{array}{l}\text { Mallinckrodt" } \\
\text { Mylan }^{\mathrm{a}}\end{array}$ & $\begin{array}{l}X \\
X\end{array}$ & $X$ & $\mathrm{X}$ & $\mathrm{X}$ & & $X$ & & & $\begin{array}{l}\mathrm{X} \\
\mathrm{X}\end{array}$ \\
\hline $\begin{array}{l}\text { Pernix } \\
\text { Therapeutics } \\
\text { Holdings }\end{array}$ & $X$ & & $\mathrm{X}$ & & $\mathrm{X}$ & & $\mathrm{X}$ & $\mathrm{X}$ & \\
\hline $\begin{array}{l}\text { Pfizer }^{\mathrm{c}} \\
\text { Purdue Pharma }^{\mathrm{d}}\end{array}$ & $\begin{array}{l}X \\
X\end{array}$ & & $X$ & & & $X$ & & & $\mathrm{X}$ \\
\hline $\begin{array}{l}\text { Teva } \\
\text { Pharmaceuticals }\end{array}$ & $\mathrm{X}$ & & & & $\mathrm{X}$ & & & & $\mathrm{X}$ \\
\hline $\begin{array}{l}\text { The Medicines } \\
\text { Company }{ }^{f}\end{array}$ & & $X$ & & & & & & & \\
\hline Zogenix $^{g}$ & $X$ & & & & $\mathrm{X}$ & & & & $\mathrm{X}$ \\
\hline
\end{tabular}

Companies identified based on whether they disclosed opioid-related marketing payments in the CMS Open Payments database between 2014 and 2019. Data in table obtained from proxy statements, annual reports, and other company filings with the US Securities and Exchange Commission from 2014 to $2020^{1}$

*Opioid products: Belbuca (buprenorphine), Bunavail (buprenorphine/naloxone), Onsolis (fentanyl). Restructuring: discontinued marketing for Bunavail (2020). Named in opioid litigation in 2018

'Opioid products: Xtampza (oxycodone), Nucynta (tapentadol). Restructuring: licensed rights to Nucynta products from Depomed (2017), completed acquisition of Nucynta products (2020). Named in opioid litigation in 2018

${ }^{7}$ Opioid products: Roxybond (oxycodone). Restructuring: terminated Roxybond licensing agreement with Inspirion Delivery Technologies to exit US pain market ${ }^{S}$ Opioid products: Lazanda (fentanyl), Nucynta (tapentadol). Restructuring: changed name to Assertio (2018). Sold Lazanda (fentanyl) to Slan (2017). Sold Gralise (gabapentin) to Alvogen (2019). Merged with Zyla Life Sciences (2020). Named in opioid litigation in 2017

"Opioid products: Oxaydo (oxycodone), Arymo (morphine). Restructuring: changed name to Zyla Life Sciences (2019). Acquired 5 NSAID products from Iroko Pharmaceuticals, Inc. (2018). Discontinued manufacture/distribution/promotion of Arymo ER (2018). Declared bankruptcy (2018). Merged with Depomed, Inc. (2020). Named in opioid litigation in 2019

"Opioid products: Belbuca (buprenorphine), Percocet (oxycodone/acetaminophen), Opana (oxycodone). Restructuring: acquired rights to Sumavel (sumatriptan) and Natesto (testosterone) (2014). Voluntarily removed Opana ER from the market after FDA request (2017). Entered into development, license, and commercialization agreement with Nevakar for 5 injectable products (2018). Companies acquired include Paladin (2014), DAVA (2014), Auxilium (2015), and Par (2015). Acquisitions helped expand portfolio with products for ADHD, pain management, urology, allergy, dermatology, orthopedics, and other generic products. Named in opioid litigation in 2014

\#Opioid products: Abstral (fentanyl). Restructuring: sold all commercial products, including Abstral, in final quarter of 2015. Merged with Sellas Life Science group (2017). Named in opioid litigation in 2017

** Opioid products: Subsys (fentanyl). Restructuring: declared bankruptcy (2019). Named in opioid litigation in 2013

Hopioid products: Duragesic (fentanyl), Nucynta (tapentadol). Restructuring: sold rights to Nucynta franchise to Depomed (2015). Named in opioid litigation in 2014

\# Opioid products: Exalgo (hydromorphone), hydrocodone products, oxycodone products. Restructuring: spun off Mallinckrodt, Inc. for generics businesses. Changed name to Sonorant Therapeutics (2019). Companies acquired include Ikaria (2015), Therakos (2015), Stratatech (2016), InfaCare (2017), Ocera Therapeutics (2017), and Sucampo (2018). Acquisitions helped expand portfolio with products for neonatal critical care, immunotherapy, skin substitutes, severe neonatal jaundice, hepatic encephalopathy, and gastrointestinal disease. Generic business declared bankruptcy (2020). Named in opioid litigation in 2017

${ }^{a}$ Opioid products: Ultiva (remifentanil). Restructuring: acquired rights to Arixtra (fondaparinux) (2014). Commercialization agreement with Theravance for pulmonary disease product (2015). Commercialization agreement with Momenta for 6 biosimilar products (2016). Launched generic version of Naloxone. Companies acquired include Jai Pharma Limited (2015) and Renaissance's topical business (2016). Acquisitions helped expand portfolio with products for women's care and dermatology. Announced merger with Pfizer (Upjohn) and other affiliated entities (2019), to be finalized. Named in opioid litigation in 2017

${ }^{b}$ Opioid products: Zutripro (hydrocodone/ chlorpheniramine/pseudoephedrine), Rezira (hydrocodone/pseudoephedrine), Vituz (hydrocodone/chlorpheniramine), Zohydro (hydrocodone). Restructuring: acquired Treximet (sumatriptan/naproxen) (2014) and Zohydro (2015). Declared bankruptcy (2019). Named in opioid litigation in 2018

cOpioid products: Troxyca (oxycodone/naltrexone). Restructuring: license agreement with Cellectis for oncology immunotherapies (2014). Commercialization agreement with OPKO Health for hGH-CTP product (2015) and with Merck KGaA for avelumab (2014). Licensing antisense therapy drug from Akcea (2019). Companies acquired include Baxter's vaccine business (2014), InnoPharma (2014), Hospira (2015), Anacor (2016), Bamboo Therapeutics (2016), Medivation (2016), AstraZeneca's small molecule anti-infective business, Array BioPharma (2019), and Therachon Holding AG (2019). Announced combination with Mylan (2019), to be finalized. Named in opioid litigation in 2018 
${ }^{d}$ Opioid products: Oxycontin (oxycodone). Restructuring: pursued FDA approval of opioid overdose reversal drug. Declared bankruptcy following settlement agreement (2019). Company dissolved as part of federal settlement, previously marketed opioid products will continue to be sold as part of a public benefit company created by the settlement. Named in opioid litigation in 2004

${ }^{\circ}$ Opioid products: Actiq (fentanyl), Fentora (fentanyl), Vantrela (hydrocodone). Restructuring: started licensing agreement with Eagle for Bendeka (2015) and with Takeda for Ninlaro (ixazomib) (2016) and Attenukine (immunocytokine) (2016). Commercialization agreement with Regeneron for fasinumab (2016) and Celltrion for two biosimilar products (2016). Stopped pursuing Vantrela ER commercialization opportunities (2017). Companies acquired include Auspex (2015) and Actavis Generics (2016), which helped expand portfolio with products for movement disorders and other generics. Named in opioid litigation in 2014

${ }^{f}$ Opioid products: Ionsys (fentanyl). Discontinued commercialization activities of Ionsys (2017). Restructuring: acquired by Novartis (2019)

${ }^{g}$ Opioid products: Zohydro (hydrocodone). Restructuring: sold Zohydro to Pernix Therapeutics (2015). Acquired Modis Therapeutics, Inc. (2019).

Named in opioid litigation in 2018

At the same time, nearly all large pharmaceutical companies have been involved in settlements related to off-label promotion, largely related to violations of the False Claims Act [3]. Past settlements and government transparency initiatives have contributed to our understanding of marketing $[2,4]$. The patterns of aggressive marketing identified in opioid settlements, which include downplaying drug risks, promoting use in vulnerable populations, marketing for unapproved indications, and providing financial inducements to providers, are not novel and have been previously documented in settlements related to illegal promotion of antipsychotics, gabapentinoids, antidepressants, and others [3].

In spite of public attention, litigation, and transparency initiatives, pharmaceutical industry marketing remains a widespread strategy for promoting new products to clinicians. Pharmaceutical company payments to physicians have remained largely stable in the past half-decade, totaling nearly $\$ 2$ billion annually with $45 \%$ of physicians receiving such payments in 2018 [4]. At the same time, court cases have challenged the enforcement of longstanding requirements under the Food, Drug, and Cosmetic Act's requirements that companies demonstrate safety and efficacy data for off-label promotion [5]. As companies continue to seek roll-back of FDA regulations on marketing, these rulings raise concerns that companies may no longer face legal consequences for promoting off-label uses of medications. In the absence of enhanced regulation of marketing, companies face few limits on applying similar tactics used to promote opioids to aggressively promote new medications [5].

\section{PATHS FORWARD}

Pharmaceutical industry marketing played a significant role in creating the nation's opioid crisis. To reduce the chance of a future marketing-induced healthcare crisis, the medical profession, pharmaceutical industry, regulators, and individual clinicians must each take concrete steps to reduce undue influences on prescribing going forward.

The 2009 Institute of Medicine (IOM) report on Conflict of Interest in Medical Research, Education, and Practice proposed 16 recommendations for physicians and medical centers to reduce undue industry influence and preserve public trust in medicine. Recommendations include banning gifts and meals and applying appropriate scrutiny to speaking and consulting arrangements [6]. Unfortunately, uptake of these recommendations has been low, and catalyzed by events like the opioid epidemic, public trust in the medical profession is eroding. Some medical centers have attempted to restrict interactions between industry sales representatives and physicians; however, these policies have been implemented heterogeneously. To help restore public trust, all medical centers and provider organizations should revise their policies on pharmaceutical detailing to fully align with IOM recommendations, develop robust mechanisms for ensuring compliance, and consider stricter oversight for high-risk drug classes such as opioids.

The Pharmaceutical Research and Manufacturers of America (PhRMA) trade group maintains a Code on Interactions with Health Care Professionals, which is substantially less stringent than IOM recommendations [7]. Recent opioid litigation suggests that this code needs to be revisited to determine whether revisions are necessary to improve corporate accountability and corporate ethical principles associated with interacting with healthcare professionals.

The FDA's Office of Prescription Drug Promotion is responsible for regulating prescription drug advertising with oversight largely consisting of reviewing industry submissions of promotional materials and concerns reported by healthcare professionals on misleading advertising. The opioid crisis has demonstrated that reliance on voluntary reporting is grossly insufficient. Policymakers should increase FDA resources to allow the agency to engage in proactive surveillance strategies to detect misleading marketing at the earliest possible moment, to support more timely review of promotional materials, which are rapidly increasing in volume, and to expand education for clinicians, such as the Bad Ad Program, focused on evaluating and reporting inappropriate prescription drug promotion.

The opioid epidemic has had devastating impacts on Americans and restoring public trust in the medical profession requires immediate proactive changes in how clinicians and policymakers approach pharmaceutical marketing. Ultimately, it is up to clinicians to learn from the opioid epidemic and lead change by forgoing marketing, pushing for reform, and choosing to interact with industry only in pursuits which are aligned with the interests of patients.

Acknowledgements: Mr. Uppal had full access to all of the data in the study and takes responsibility for the integrity of the data.

Corresponding Author: Timothy S. Anderson, MD, MAS; Division of General Medicine, Beth Israel Deaconess Medical Center, 1309 
Beacon Street, Brookline, Boston, MA 02246, USA (e-mail: tsander1@bidmc.harvard.edu).

\section{Declarations:}

Conflict of Interest: Dr. Anderson reports receiving grants from the National Institute on Aging and American College of Cardiology outside of the submitted work.

Disclaimer: The contents represent the views of the authors only and not necessarily those of Beth Israel Deaconess Medical Center or Harvard University.

\section{REFERENCES}

1. Electronic Data Gathering, Analysis, and Retrieval system. United States Securities and Exchange Commission. . https://www.sec.gov/edgar/ search-and-access

2. Schwartz LM, Woloshin S. Medical Marketing in the United States, 19972016. JAMA. 2019;321(1):80-96. doi:https://doi.org/10.1001/jama.2018. 19320
3. Arnold DG, Stewart OJ, Beck T. Financial Penalties Imposed on Large Pharmaceutical Firms for Illegal Activities. JAMA. 2020;324(19):19951997. doi:https://doi.org/10.1001/jama.2020.18740

4. Marshall DC, Tarras ES, Rosenzweig K, Korenstein D, Chimonas S. Trends in Industry Payments to Physicians in the United States From 2014 to 2018. JAMA. 2020;324(17):1785-1788. doi:https://doi.org/10.1001/ jama.2020.11413

5. Robertson C, Kesselheim AS. Regulating off-label promotion-a critical test. N Engl J Med. 2016;375(24):2313-2315.

6. Lo B, Field MJ, Institute of Medicine (US) Committee on Conflict of Interest in Medical Research, Education, and Practice, eds. Conflict of Interest in Medical Research, Education, and Practice. Washington (DC): National Academies Press (US); 2009.

7. PhRMA. Code on Interactions with Health Care Professionals. . https:// www.phrma.org/-/media/Project/PhRMA/PhRMA-Org/PhRMA-Org/ PDF/A-C/Code-of-Interaction_FINAL21.pdf

Publisher's Note: Springer Nature remains neutral with regard to jurisdictional claims in published maps and institutional affiliations. 